\title{
IV \\ OS ROYALTIES DE ITAIPU NA EDUCAÇÃO: UMA ANÁLISE PRELIMINAR NOS MUNICÍPIOS LINDEIROS NO OESTE DO PARANÁ (1985-2017)*
}

Juliana Schwaab Thibes

João Carlos da Silva

\section{INTRODUÇÃO}

A construção da usina hidrelétrica Binacional de Itaipu a partir de 1974, proporcionou mudanças no cenário econômico, social e territorial nos municípios lindeiros ao lago de Itaipu. Grande parte da população que vivia em áreas rurais foi evacuada, deixando terras produtivas submersas a uma grande quantidade de água, para assim, dar lugar ao grandioso projeto da construção da maior hidrelétrica do mundo da época. Após ter ocorrido o alagamento e a usina de Itaipu iniciar sua comercialização de energia em 1985, os municípios passaram então a receber os royalties mensalmente, conforme previsto na Constituição Federal de 1988.

Desta forma, o presente trabalho tem como proposta realizar uma breve análise da aplicabilidade na educação pelos municípios lindeiros ao lago de Itaipu que recebem as maiores quantidades royalties pago pela Hidrelétrica Binacional de Itaipu, delimitando nos municípios de Santa Helena e Itaipulândia. Para chegarmos aos resultados dos investimentos realizados na educação por estes municípios, se faz necessário inicialmente compreender o significado dos royalties, como a Itaipu foi idealizada, projetada e concluída, bem como os principais acontecimentos daquele período.

\section{OS ROYALTIES E A EDUCAÇÃO}

O termo royalties, plural da palavra royalty em inglês, designa regalia ou privilégio, consistindo em uma quantia paga por alguém ao proprietário pelo direito de usar, explorar ou comercializar um produto, obra ou terreno. Em nosso país os royalties são pagos por várias explorações de fontes naturais como é o caso do petróleo, minerais e potenciais de energia hidráulica.

"DOI - 10.29388/978-65-86678-77-2-0-f.53-64 
A Constituição Federal de 1988, em seu Artigo 20으, define como um dos bens da União, os potenciais de energia hidráulica e garante compensação financeira aos Estados, Distrito Federal, Municípios e Órgãos da União em caso de exploração de recursos hídricos para a geração de energia elétrica.

O Decreto Federal no 1 de 11 de janeiro de 1991 estabelece a compensação financeira pela utilização dos recursos hídricos o cálculo e a distribuição mensal decorrentes ao aproveitamento dos recursos hídricos, para a geração de energia elétrica, bem como os royalties devidos pela Itaipu Binacional ao Governo Brasileiro, estabelecidos pelo Tratado de Itaipu.

A Lei $n=8.001 / 90$, recentemente alterada pela Lei no 13.661 de 8 de maio de 2018, prevê a distribuição mensal dos royalties, estabelecendo o pagamento de 25\% aos Estados; 65\% aos municípios; 3\% ao Ministério do Meio Ambiente; 3\% ao Ministério de Minas e Energia; $4 \%$ ao Fundo Nacional de Desenvolvimento Científico e Tecnológico.

Com a legislação dos royalties e a comercialização da energia elétrica produzida pela Usina de Itaipu, iniciou-se o repasse mensal beneficiando 15 municípios do Estado do Paraná e 01 do Estado do Mato Grosso do Sul que foram afetados pelo alagamento, sendo o valor proporcional a quantidade de área alagada.

A tabela a seguir demonstra os 16 municípios beneficiários dos royalties, seguido pelo montante recebido no mês de janeiro de 2017 e a quantidade de área submersa pelo lago, conforme publicação da Aneel. Podemos observar que os municípios mais beneficiados com os royalties são: Santa Helena, Foz do Iguaçu e Itaipulândia.

Tabela 1. Indicação dos Municípios, áreas alagadas e o repasse dos royalties em dólar repassado em janeiro de 2017

\begin{tabular}{|c||c||c|}
\hline \multicolumn{1}{|c||}{ Município } & Repasse atual & Área alagada $\mathbf{~ k m}^{\mathbf{2}}$ \\
\hline \hline Foz do Iguaçu & US\$ 787,5 mil & 201,84 \\
\hline \hline Santa Terezinha de Itaipu & US\$ 163,5 mil & 41,90 \\
\hline \hline São Miguel do Iguaçu & US\$ 354,7 mil & 90,91 \\
\hline \hline Itaipulândia & US\$ 701,3 mil & 179,73 \\
\hline \hline Medianeira & US\$ 4,5 mil & 1,16 \\
\hline \hline Missal & US\$ 156,3 mil & 40,07 \\
\hline \hline Santa Helena & US\$ 1.029 mil & 263,76 \\
\hline \hline Diamante do Oeste & US\$ 21,9 mil & 5,62 \\
\hline \hline São José das Palmeiras & US\$ 7,6 mil & 1,94 \\
\hline \hline Marechal Cândido Rondon & US\$ 218,7 mil & 56,04 \\
\hline \hline
\end{tabular}




\begin{tabular}{|c||c||c|}
\hline Mercedes & US\$ 75,4 mil & 19,32 \\
\hline \hline Pato Bragado & US\$ $183,7 \mathrm{mil}$ & 47,07 \\
\hline \hline Entre Rios do Oeste & US\$ $128,4 \mathrm{mil}$ & 32,90 \\
\hline \hline Terra Roxa & US\$ 6,2 mil & 1,58 \\
\hline \hline Guaíra & US\$ $199 \mathrm{mil}$ & 51,01 \\
\hline \hline Mundo Novo (MS) & US\$ $57,4 \mathrm{mil}$ & 14,71 \\
\hline
\end{tabular}

Fonte: Aneel (2007).

O crescimento industrial brasileiro estava em alto nível de desenvolvimento e a necessidade de fazer suas máquinas produzirem, levou o consumo elétrico à beira de uma crise energética, pois a energia já em crise, em pouco tempo não seria mais suficiente para abastecer as grandes cidades industriais:

Os argumentos utilizados para justificar o projeto estavam apoiados nas ideias dos militares de tornar o Brasil uma grande potência. E, para o desenvolvimento do país, era necessário produzir energia elétrica. Dentro deste contexto, em 1974 foi criada a entidade Itaipu Binacional e no ano seguinte foi dado início às obras (MASCARENHAS, 2010 p.80).

O Rio Paraná, em seu grande volume de água, seria o ideal para a construção de uma usina hidrelétrica, porém havia a divisão entre Brasil, Paraguai e Argentina, o qual o Rio percorria que poderia tornar-se um empecilho, sendo a vontade dos idealizadores que a usina pertencesse somente ao Brasil, não havendo assim, a necessidade de divisão com os outros países.

Conforme Mazzarollo (2003), depois de estudos técnicos, realizou-se em 1966, na cidade de Foz do Iguaçu um acordo diplomático entre Brasil e Paraguai, sendo assinada a Ata do Iguaçu, como demonstração de interesse em aproveitar esse potencial energético.

Em abril de 1973, Brasil e Paraguai vieram a assinar o acordo, que ficou conhecido como "Tratado de Itaipu", com a finalidade de usufruírem os recursos hídricos do rio Paraná, que tinha como percurso o Salto de Sete Quedas até a Foz do Rio Iguaçu. Foi necessário inundar uma área com cerca de $1.400 \mathrm{~km}^{2}$, sendo $800 \mathrm{~km}^{2}$ do lado brasileiro e $600 \mathrm{~km}^{2}$ do lado paraguaio. $\mathrm{Em}$ 1974, com a chegada das primeiras máquinas iniciou-se a construção da maior usina hidrelétrica do mundo.

Foz do Iguaçu que possuía cerca de 20 mil habitantes e apenas duas ruas asfaltadas passou por uma transformação drástica e em 10 anos a 
população saltou para mais de 100 mil habitantes. Entre os anos de 1975 e 1978 foram construídas mais de 9 mil casas dos dois lados dos países para acomodar os trabalhadores que vieram de toda a parte do Brasil, sendo ainda construído hospitais, escolas, igrejas, clubes e centros esportivos para melhor atendê-los.

A primeira tarefa que os operários tinham era alterar o curso do rio, sendo necessário escavar $2 \mathrm{~km}$ de extensão, 150 metros de largura e 90 metros de profundidade para fazer o desvio, onde seria construída a barragem em concreto. Este trabalho terminou em 20 de outubro de 1978, e em novembro deste mesmo foram lançados 7.207 metros cúbicos de concreto na obra.

A construção da usina gerou muitos empregos diretos e indiretos, fazendo com que a economia dos dois países aumentasse significativamente. $O$ PIB - Produto Interno Bruto do Paraguai, que já havia aumentado em $5 \%$ no ano de 1975 , cresceu 10,8 em 1978. No auge da construção, havia cerca de 40 mil trabalhadores e entre os anos de 1975 e 1981, chagava a ser contratada até 5 mil pessoas por mês, devido ao extenso período e da rotatividade da mão-de-obra.

Com a barragem construída, o próximo passo seria a montagem das unidades geradoras, o que gerou outro desafio, pois a roda da turbina pesava cerca de 300 toneladas e vinha do Estado de São Paulo, sendo que a primeira entrega demorou aproximadamente 3 meses para chegar em seu destino final.

A última etapa e não menos dificultosa que os dirigentes e técnicos da Itaipu deveriam realizar, seria a desapropriação das terras dos agricultores que ocupavam parte da área que seriam atingidas pelo lago de Itaipu. Sendo que cada propriedade era avaliada pelos próprios funcionários da Itaipu de forma arbitrária e injusta:

$\mathrm{Na}$ área necessária para a imponente hidrelétrica viviam aproximadamente 8.000 famílias (cerca de 40.000 mil pessoas) na margem brasileira e 4.000 mil famílias (20.000 mil pessoas) na margem paraguaia. Todas foram forçadas a deixar suas terras, casas e benfeitorias, e lançar-se na luta pela reestruturação de suas vidas, família e comunidades. Os que tinham propriedade foram indenizados, e entre estes houve os que conseguiram fazer bons negócios e também os que se arruinaram. Mas havia muitos que nada possuíam (posseiros, arrendatários, empregados e bóias-frias), e estes, salvo exceções, tiveram de abandonar a área de mãos vazias, lançados à própria sorte (MAZZAROLLO, 2003, p.40). 
A barragem ficou pronta em outubro de 1982, iniciando-se outra etapa que era resgatar os animais que viviam na área que seria inundada, chegando a serem salvos cerca de 36.450 animais, conforme fontes da Itaipu.

Para Mascarenhas (2010) a construção da usina além de trazer impactos sociais também causou grandes impactos ambientais como a perda da vegetação, da fauna, alteração na fauna do rio, migrações de peixes, o desaparecimento do Salto de Sete Quedas, além de perdas históricas, culturais e arqueológicos:

Em 1982, foi aprovado, pela Itaipu Binacional, o Plano de Utilização da Área do Reservatório, onde ficou estabelecida e regulamentada a política da entidade, com respeito a continuidade das providências de caráter ecológico, quanto à implantação dos usos múltiplos que as águas do reservatório proporcionaram: pesca, turismo lazer, abastecimento urbano e industrial, irrigação e outros (PERIS, 2003, p. 148).

No dia 05 de novembro de 1982, os presidentes do Brasil, João Figueiredo e do Paraguai, Alfredo Stroessner, inauguram oficialmente a maior hidrelétrica do mundo, acionando o mecanismo que levanta automaticamente as 14 comportas do vertedouro, liberando a água represada do Rio Paraná.

De acordo com a história divulgada no próprio site da Itaipu, o primeiro giro mecânico de uma turbina ocorreu em dezembro de 1983 e em março de 1985 a energia elétrica passa finalmente a ser comercializada. Em 1997, a Itaipu Binacional passa a abastecer $26 \%$ da demanda do setor elétrico do país. No ano 2000 atinge o recorde de produção, gerando 93,4 bilhões de quilowatts-hora. $O$ custo da construção da maior usina hidrelétrica do mundo chega a US\$ 14 bilhões, sendo o valor atualizado em US\$ 16 bilhões de dólares, sendo as dívidas com prazo de pagamento até o ano de 2023.

A energia produzida pela gigantesca usina hidrelétrica de Itaipu é enviada para abastecer o sudeste do país, não sendo aproveitado em nenhuma cidade do Paraná, o que causa muita indignação pelos moradores da região lindeira ao lago de Itaipu.

Os municípios de Santa Helena e Itaipulândia, conhecidos no oeste paranaense por serem os recebedores das maiores parcelas de royalties e com alto potencial de investimentos, foram cogitados a se igualar a países de primeiro mundo a partir do recebimento dos royalties.

Itaipulândia, considerado o terceiro município recebedor das maiores parcelas de royalties de Itaipu, está situado no extremo oeste Paranaense, localizado a uma distância de $630 \mathrm{~km}$ da capital do estado. A população atual de acordo com fontes do IBGE é de 10.413 habitantes, com uma área de 
aproximadamente $331,288 \mathrm{~km}^{2}$. O Índice de Desenvolvimento Humano em 2010 foi de 0,738 .

Em 1961, vieram os primeiros pioneiros advindos dos Estados de Santa Catarina e Rio grande do Sul para essa região e cultivavam principalmente, fumo, feijão, milho, mandioca, criavam suínos e bovinos para sua subsistência, e ainda, cultivavam o fumo para a comercialização. Em 1966 foi construída a primeira igreja e o prédio servia também como escola para a comunidade.

Para Scarpato e Böhm (2006) as primeiras escolas, em sua maioria, foram construídas com o auxílio de moradores em forma de mutirão, onde era construída apenas uma sala de aula. Os terrenos eram cedidos por agricultores e os professores eram contratados e pagos com recursos públicos. A partir da década 1970 é que o poder público municipal ficou responsável pela manutenção do ensino conforme explica Balzan (2014).

Durante a década de 1970, a presença do poder público municipal na oferta da escolarização passou a ser reivindicada pelos colonos. Assim, o município de São Miguel do Iguaçu passou a assumir a responsabilidade pela manutenção das escolas, contrato e pagamento de professores, fornecimento de material didático e controle sobre os programas e conteúdos a serem ensinados. Com isso, em algumas escolas houve também oferta do ginásio (5a a 8 a série). Os grupos escolares, com seriação, professores habilitados, conteúdos organizados substituíram as primeiras escolas dos colonos, principalmente por causa da grande demanda de alunos, em decorrência da explosão demográfica que ocorreu a partir do início da década de 1970. No entanto, devido à construção da Hidrelétrica de Itaipu e o alagamento de grande parte do território que veio a pertencer a Itaipulândia, tanto o número de escolas quanto a quantidade de matrículas diminuiu, devido ao êxodo de milhares de pessoas da região (BALZAN, 2014, p. 43).

Em março de 1992, Itaipulândia tornou-se um município a partir de sua emancipação pela Lei Estadual no 9.908/92. Com a construção da Usina Hidrelétrica de Itaipu, metade de suas terras antes utilizadas com a agricultura foram inundadas pelo lago, causando muitos impactos, entre os quais, o desalojamento de milhares de pessoas em virtude da grande quantidade de terras submersas pela formação do lago de Itaipu.

Scarpato e Böhm (2006) relatam que a Itaipu desapropriou uma área total de 111.332 hectares onde viviam mais de 40.000 brasileiros, causando a migração dessas pessoas para outras regiões como Mato Grosso e Paraguai, também provocou uma movimentação demográfica interna no espaço do Distrito de Aparecidinha do Oeste, onde posteriormente seria a sede do 
Município de Itaipulândia, recebendo muitos moradores. Apontam ainda sobre a inviabilidade econômica:

Logo se percebeu que não haveria sustentabilidade e viabilidade econômica, pois aos poucos a população foi diminuindo. O hospital que havia sido instalado fechou as portas e deixou de atender a população. $O$ mesmo aconteceu com a agência bancária do Bradesco (SCARPATO; BÖHM, 2006, p. 124).

Em 2010, o número de habitantes chegava a 9.000, sendo possível destacar o alto índice de pessoas que se evadiram do município de Itaipulândia.

De acordo com informações da secretaria municipal de educação no ano de 2017, o município de Itaipulândia contava com 05 centros municipais de educação infantil, com 420 alunos matriculados; 04 escolas municipais, com 989 alunos matriculados; 01 escola modalidade especial, com 39 alunos matriculados; 02 escolas estaduais de Ensino Fundamental Fase Final com 656 matrículas; 02 Escolas de Ensino Médio, com 298 alunos matriculados e 02 escolas de Educação de Jovens e Adultos com 100 matrículas.

O município de Itaipulândia já foi beneficiado com os royalties de Itaipu entre os anos de 1997 a 2017 em mais de R\$ 610.000.000,00 (seiscentos e dez milhões de reais) segundo informações publicadas pela Aneel. Isso fez com que o município de Itaipulândia se tornasse o município com maior investimento per capita como explica Toillier apud Balzan (2014):

Segundo estudos da Fundação Getúlio Vargas de 2007, Itaipulândia foi o município brasileiro com maior investimento per capita em saneamento básico e saúde no ano de 2000; em 2007 foi o município que mais investiu em educação no Paraná, com o investimento de $106,39 \%$ da sua arrecadação de impostos, quando o mínimo exigido por lei é de $25 \%$, ou seja, todo o valor arrecadado pelo município, além de uma parte dos royalties; segundo o levantamento do Departamento de Economia Rural do Estado do Paraná (DERAL) é o 26ㅇ município do Paraná em destaque no agronegócio, algo digno de reconhecimento, uma vez que o município é pequeno se comparado com outros, além de investir nas áreas de desenvolvimento rural sustentável e cuidado com matas ciliares; e finalmente, com uma parceria com a Itaipu Binacional, reduziu a zero os passivos ambientais de suas microbacias hidrográficas, sendo o primeiro município da Bacia do Paraná III que abrange a região Oeste do Paraná (TOILLIER apud BALZAN, 2014, p. 39). 
Podemos verificar que o município realizou grandes investimentos no que diz respeito a educação aplicando $81,39 \%$ a mais que o exigido por lei. De acordo com uma breve pesquisa realizada no município de Itaipulândia, percebemos que os maiores investimentos foram destinados à educação infantil, sendo construídas instituições e contratado profissionais para atender e assegurar o direito da criança em frequentar a educação infantil, extinguindo praticamente a lista de espera por vagas.

Outro investimento que demandou altos investimentos, diz respeito ao ensino técnico em nível médio e ensino superior, onde o município contratou empresas para prestarem serviços de transporte de alunos para outros municípios, além do fornecimento de subsídios de estudo, no qual o aluno pode receber um auxílio financeiro no valor de $\mathrm{R} \$ 500,00$ à $\mathrm{R} \$ 600,00$ mensais para custeio das mensalidades de instituições privadas.

O Município de Santa Helena encontra-se aproximadamente a $620 \mathrm{Km}$ da capital do estado - Curitiba, no Centro da Costa Oeste do Paraná, conhecida também como "Terra das Águas" por ter grande parte de suas terras alagadas pelo lago de Itaipu, onde ficou praticamente ilhada. De acordo com dados do IBGE (2016) a população está estimada em 25.665 habitantes, possuindo uma área territorial aproximadamente em $758,23 \mathrm{~km}^{2}$.

Santa Helena limita-se ao norte com o município de Entre Rios do Oeste, ao sul com Missal e Itaipulândia, ao leste com São José das Palmeiras e Diamante do Oeste, ao oeste com a República do Paraguai através do lago de Itaipu. O IDH do município em 2010 foi de 0,744.

De acordo com Colodel (1988) Santa Helena, teve seus primeiros colonizadores por volta de 1920, advindos dos Estados do Rio Grande do Sul e Santa Catarina, com atrativo de terras férteis e baixos preços. Em 1924, com a luta revolucionária de Luís Carlos Prestes o fluxo de colonizadores foi reduzido pelo fato de a região ser palco de guerra.

Entre os anos de 1920 a 1960, os colonos trabalhavam praticamente em regime de subsistência, cultivando principalmente mandioca, milho, trigo, arroz, feijão, garantindo as necessidades da família e o pouco excedente destinava-se a comercialização principalmente no município de Foz do Iguaçu.

Conforme Colodel (1988) em 1960 começou a funcionar a primeira escola nas dependências da igreja Católica, onde os alunos permaneceram estudando até 1962, quando um vendaval derrubou as estruturas da igreja, passando a ser construído duas salas de aula pela prefeitura de Medianeira a qual Santa Helena se fazia distrito.

Após a emancipação política em 1967, foram criadas as primeiras escolas municipais rurais que ficaram sobre responsabilidade do município pela manutenção do prédio escolar e o pagamento dos professores. 
Com a formação do lago de Itaipu, Santa Helena sofreu grande impacto socioeconômico, onde milhares de pessoas foram obrigadas a saírem de suas terras, abandonando assim, anos de trabalho e conquistas, para um futuro incerto. A redução populacional, ocasionou uma depressão no comércio, fazendo com que muitos comerciantes fechassem suas portas. Muitas escolas foram fechadas por falta de alunos, conforme corrobora Sterchile (2006).

Segundo Sterchile (2006) em 1980 o município contava com 67 escolas, e com o alagamento muitos moradores migraram para outras regiões, sendo que em 1985 dezessete escolas foram fechadas. Restaram-se então 49 escolas rurais municipais e 9 dessas escolas passaram a pertencer ao município de São José das Palmeiras a partir de sua emancipação em 1985.

Desta forma evidenciamos, que os principais motivos pela evasão da população no município de Santa Helena, se deu principalmente pela formação do reservatório do lago de Itaipu, posteriormente pela emancipação do município de São José das Palmeiras e pela mecanização agrícola, fazendo com que muitas pessoas fossem em busca de novos campos de trabalho em outras cidades. A seguir poderemos observar através da tabela as variações populacionais no município de Santa Helena entre os anos de 1970 a 2010.

Tabela 2. Índice populacional no município de Santa Helena nos anos de 1970, 1980, 1991, 2000 e 2010

\begin{tabular}{|c|c|c|c|c|c|}
\hline Ano/Censo & 1970 & 1980 & 1991 & 2000 & $\mathbf{2 0 1 0}$ \\
\hline População & 26.834 & 34.882 & 18.861 & 20.491 & 23.413 \\
\hline
\end{tabular}

Fonte: Prefeitura Municipal de Santa Helena (2015).

Anita Martins apud Fochezatto (2012), realizou estudos sobre o esvaziamento escolar no município de Santa Helena a partir do projeto Itaipu, constatando um significativo processo de evasão escolar naquele período, sendo que várias escolas foram fechadas devido a indenização e outras por falta de alunos.

[...] vemos [...] que o município de Santa Helena, no decorrer dos anos de 1971 a 1986, teve 106 escolas de 1a a 4a séries das quais, 10 passaram a pertencer ao Município de São José das Palmeias, 28 foram desapropriadas pela Itaipu Binacional, 26 foram extintas por faltas de alunos, restando em Santa Helena apenas 43 escolas (MARTINS apud FOCHEZATTO, 2012, p. 115).

O município de Santa Helena, no ano de 2017, contava com 07 Centros de Educação Infantil com 562 alunos matriculados, 10 Escolas da rede Municipal com 2.325 alunos matriculados, 08 Escolas Estaduais Ensino 
Fundamental Fase Final com 1.200 alunos matriculados, 04 Escolas Estaduais modalidade Ensino Médio com 757 matrículas efetivadas, 02 Escolas de Educação de Jovens e Adultos com 246 matrículas, 06 escolas de Educação Especial com 53 matrículas efetivadas e por fim, 01 Universidade Federal, Universidade Tecnológica Federal do Paraná (UTFP) que iniciou suas atividades, nas antigas instalações da Universidade do Oeste do Paraná (UNIOESTE), ofertando 02 cursos: Bacharelado em Ciência da Computação e Licenciatura em Ciências Biológicas.

Em relação aos royalties, o município de Santa Helena foi o mais beneficiado, sendo depositado aos cofres públicos mais $\mathrm{R} \$ 910.000 .000,00$ (novecentos e dez milhões de reais) desde o ano de 1997 até 2017 conforme relatório publicado pela Aneel.

De acordo com a pesquisa realizada no município, Santa Helena também teve seus principais investimentos voltados para a educação infantil e o ensino superior. Nos últimos anos foram construídos espaços para a destinação ao atendimento à educação infantil, além da contratação de mais de 90 professores de educação infantil, através de concurso público, além da contratação de 100 bolsas de estudo de uma escola privada. Hoje o município ainda possui uma pequena lista de espera de crianças que aguardam serem chamados para frequentar a educação infantil.

No que se refere aos investimentos no ensino superior, os alunos conquistaram o direito de receber $70 \%$ do valor pago ao transporte intermunicipal, além do município ter investido na construção de uma estrutura que foi cedida inicialmente para atender a UNIOESTE e que hoje foi doada para atender a UTFP, que oferta 03 cursos (Agronomia, Ciências Biológicas, Ciências da Computação).

A educação básica, na modalidade Ensino Fundamental - fase inicial, também receberam investimentos, como reformas de escolas, construção de uma nova escola, reforma e construção de Ginásios de Esportes, os quais são utilizados para aulas de educação física de algumas escolas, entre outras melhorias que proporcionaram qualitativamente na educação do município.

\section{CONSIDERAÇÕES FINAIS}

Podemos concluir que a construção da imponente usina hidrelétrica de Itaipu trouxe diversos impactos para a região oeste paranaense, tanto no que diz respeito a fatores econômicos, quanto sociais. Os municípios de Santa Helena e Itaipulândia tiveram importantes prejuízos no que se refere às percas territoriais, onde um grande número de pessoas teve que deixar seus lares em busca de novas oportunidades de vida em outras cidades e estados. A 
economia estagnou, os comércios ficaram vazios e ainda, grande parte das terras antes produtivas ficaram submersas as águas do lago de Itaipu, deixando de produzir milhares de toneladas de milho e soja por ano.

$\mathrm{Na}$ questão social, a população também foi prejudicada, pois famílias, vizinhos, comunidades foram desfeitos em prol da Itaipu, o suor e o desgaste físico daqueles que desbravaram matas fechadas para transformar em moradias, plantações e pequenas comunidades, viram seus sonhos destruídos. Escolas foram desapropriadas e muitas outras fechadas devido à falta de alunos, um vazio tomou conta.

A compensação financeira paga através dos royalties pela Itaipu a estes municípios, é considerada de extrema importância, pois a partir desse montante é que os municípios puderam se reerguer e superar alguns traumas trazido pela construção da hidrelétrica. Podemos considerar também, que apenas com o pagamento dos royalties é que foram possíveis inúmeros investimentos que foram destinados à educação, saúde, infraestrutura, entre outros, como podemos citar o município de Santa Helena que realizou reformas em escolas, ginásios de esportes, construção de salas de aula, construções de centros municipais de educação infantil, prédio para instalação de uma universidade e ainda o município de Itaipulândia que chegou a aplicar mais de $106 \%$ na educação no ano de 2007.

Esperamos com este artigo, ainda que preliminarmente, contribuir com as reflexões acerca dos investimentos nas escolas públicas nos municípios lindeiros, a partir dos investimentos resultantes dos royalties da usina de Itaipu.

\section{REFERÊNCIAS}

\section{BALZAN, C. S. Os desafios da implantação e implementação da pedagogia históricocrítica nos anos iniciais do ensino fundamental em Itaipulândia. Cascavel, 2014. Dissertação (Mestrado em Educação). UNOESTE, Campus Cascavel.}

COLODEL, J. A. Obras e Companhias Colonizadoras. Cascavel: Assoeste, 1988. COLODEL, J. A. História de Santa Helena: descobrindo e aprendendo: ensino fundamental. Santa Helena: Prefeitura Municipal, Secretaria de Educação e Cultura, 2000.

FOCHEZATTO, A.; KUIAVA, J. Reflexos de um Regime Tecnocrático/Autoritário: Influência do Projeto Itaipu no Contexto Escolar do Município de Santa Helena. In. SILVA, João Carlos da Silva; CASTANHA, André Paulo; ORSO, Paulino José 
ZANOTTO, Marijane. História da Educação: escola pública e práticas educativas. Cascavel: Edunioeste, 2012.

MAZZAROLLO, J. A Taipa da Injustiça. 2a ed. São Paulo. Edições Loyola. PERIS, A. F. Estratégias de Desenvolvimento Regional: Região Oeste do Paraná. Vários autores. - Cascavel: Edunioeste, 2003.

SBARDELOTTO, D. K. CORREA, J. J. História da Criação do Colégio Bartolomeu Mitre, o Primeiro Grupo Escolar do Oeste do Paraná: Contexto Histórico (1889 a 1930). In.

CASTANHA, André Paulo; ORSO, Paulino José; SILVA, João Carlos da; BATISTA, Marco Antônio. História da Educação: Levantamentos de Fontes e Instituições Escolares. Org. Carvalho. Cascavel: Edunioeste, 2010.

SCARPATO, R.; BÖHM, I. História de Itaipulândia. 1a edição. Cascavel, PR: Assoeste Ltda, 2006.

STERCHILE, Adriela. Aspectos da História das Instituições Escolares de Santa Helena. 2006. 39 f. Trabalho. (Especialização em História da Educação Brasileira) - Universidade do Oeste do Paraná, UNIOESTE. Cascavel, Paraná.

\section{SITES CONSULTADOS:}

http://www.planalto.gov.br/ acesso em: 29 jan. 2017

http://www.ibge.gov.br/ acesso em: 28 fev. 2017

http://www.santahelena.pr.gov.br/ acesso em: 01 fev. 2017

https://www.itaipu.gov.br/nossa-historia) acesso em: 29 jan. 2017

http://www.itaipulandia.pr.gov.br acesso em: 01 mar. 2017

http://www4.pr.gov.br/escolas/numeros/ acesso: em 20 mar. 2017 